\title{
Repurposing the Selective Oestrogen Receptor Modulator Tamoxifen for the Treatment of Duchenne Muscular Dystrophy
}

\author{
Elinam Gayi§, Laurence A. Neff, Hesham M. Ismail, Urs T. Ruegg, Leonardo Scapozza, and Olivier \\ M. Dorchies*
}

§SCS-DSM Award for best poster presentation in Medicinal Chemistry

\begin{abstract}
Drug discovery is a long, expensive and risky process. Evaluating drugs that have already been proved safe for use in humans and testing them for a new indication greatly reduces the time and monetary costs involved in finding treatments for life-threatening conditions. Here tamoxifen, a drug that is used for the treatment of breast cancer, is investigated in a mouse model of Duchenne muscular dystrophy. Tamoxifen was efficacious in countering the symptoms of the disease without affecting the underlying genetic cause. Based on these results, tamoxifen has been tested in other forms of muscle disease with success. Drug repurposing may not only be a cost-effective manner for treating a variety of diseases, it may also help us uncover common mechanisms between conditions that were previously thought to be unrelated.
\end{abstract}

Keywords: Duchenne muscular dystrophy · Oestrogens · Repurposing · SERM · Tamoxifen

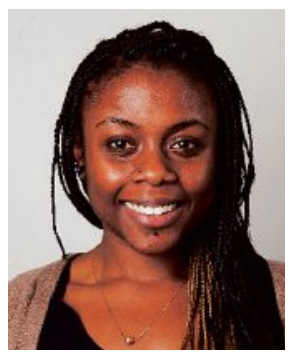

Elinam Gayi obtained a Bachelor degree in Physiological sciences from the University of Bristol, UK, in 2009. She then returned to Geneva to do a Master in Neuroscience under the supervision of Prof. Pegna. She is currently doing a PhD at the School of Pharmaceutical Sciences in Prof. Scapozza's lab and under the supervision of Dr. Dorchies. The work presented here forms the basis of her PhD project, which focuses on the role of oestrogens in muscle diseases, in particular Duchenne muscular dystrophy and X-linked centronuclear (myotubular) myopathy.
Development of a new drug is a long, expensive and risky process that usually takes 10 to 15 years. ${ }^{[1]}$ With the increasing costs involved in bringing a new drug to the market, repurposing approved drugs for new indications is a cost-effective manner to make more treatment options available to patients. ${ }^{[2]}$ Furthermore, most of these compounds are off-patent and therefore readily available at low cost.

Duchenne muscular dystrophy (DMD) is a genetic disorder that affects 1:3500 male births. It is characterized by progressive muscle degeneration and weakness due to the lack of a large subsarcolemmal protein called dystrophin. ${ }^{[3]}$ The lack of dystrophin leads to membrane instability, increased calcium influx and oxidative stress. This disrupts muscle cell homeostasis, which impairs force generation and eventually leads to muscle cell death. Inflammation then ensues with part of the muscle tissue being replaced by fibrotic scars and adipose tissue further aggravat- ing the condition. ${ }^{[3]}$ There is currently no cure for DMD. Many patients undergo physiotherapy to improve posture and reduce loss of movement; some eventually require scoliosis surgery and mechanical ventilation. Glucocorticoids prolong ambulation and slow the progression of the disease; however, many patients stop treatment due to undesirable side effects. Despite these interventions, many succumb to the disease in their third decade of life. ${ }^{[4]}$ Understanding the mechanisms involved in the pathogenesis can allow seeking and developing new therapies that are more efficacious and better tolerated by patients. ${ }^{[5]}$

Oestrogens have long been considered as female reproductive hormones, however, they have recently been found to be present - and have effects - in many tissues in both men and women. ${ }^{[6]}$ They are formed by the aromatization of androgens by the enzyme aromatase. Aromatase is abundantly expressed in gonads, but low a

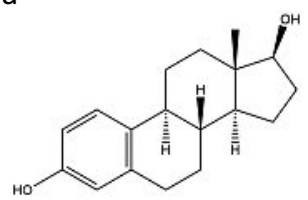

b

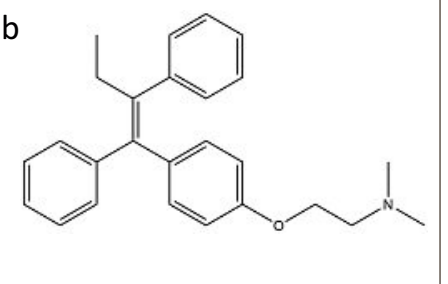

Fig. 1. (a) Structure of $17 \beta$-oestradiol and (b) structure of tamoxifen. 
activities are also found in other tissues including adipose tissue, bone, brain, ${ }^{[7]}$ and interestingly in skeletal muscle. ${ }^{[8]}$ The biological effects of oestrogens, of which $17 \beta$-oestradiol (Fig. 1) is the most abundant one, occur mainly through the nuclear oestrogen receptors, ER $\alpha$ and ER $\beta$, both of which have been shown to be expressed in skeletal muscle. ${ }^{[9,10]}$ Classically, binding of oestradiol to its receptors leads to dimerisation of the receptor and binding to oestrogen response elements (EREs) found in the promoter region of specific genes..$^{[1-13]}$ In parallel, binding of ligands to oestrogen receptors leads to conformational changes allowing co-activator proteins to be recruited[13] (Fig. 2).

Evidence for the beneficial effects of oestrogen signalling in skeletal muscle can be found in retrospective studies of post-menopausal women on hormonereplacement therapy (HRT) to control the symptoms of menopause. ${ }^{[14]}$ Studies indicate that women on HRT not only have preserved strength compared to age-matched women not on HRT, but that they also have less fatty infiltration that is associated with ageing. ${ }^{[15,16]}$ Changes in strength during the menstrual cycle have also been noted. [17,18] In addition to HRT studies, many studies have also been performed in ovariectomised mice. In these studies, removal of the ovaries - the main source of oestradiol - led to a decrease in both force production and spontaneous locomotor activity. ${ }^{[19]}$ When oestradiol was administered to the ovariectomised mice, these effects were reversed suggesting that oestrogens play a role in the protection and maintenance of skeletal muscle.

Tamoxifen (Fig. 1b) is a safe and readily available anticancer drug that has been used to treat breast cancer for the past 40 years. ${ }^{[20]}$ Tamoxifen and several of its metabolites are selective oestrogen receptor modulators (SERM); depending on the tissue in which they act, they can have pro- or anti-oestrogenic effects.[21] This is of particular interest in the treatment of breast cancer as not only do they have anti-oestrogenic effects in breast tissue but they also have pro-oestrogenic effects in bone, which prevents further osteoporosis in a population already at risk. ${ }^{[22]}$ Tamoxifen and its active metabolites have a variety of other actions; they can act as membrane stabilizers, anti-oxidant, antifibrotic agents, and modulators of calcium handling. ${ }^{[23]}$ All these actions are relevant to major dysfunctional pathways involved in DMD pathology, making tamoxifen an interesting candidate for the treatment of DMD. Our lab therefore evaluated the spectrum of efficacy of tamoxifen in a murine model of DMD, the $m d x^{5 C v}$ mouse. [24]

Briefly, male $m d x^{5 C v}$ mice were given free access to standard mouse chow sup-

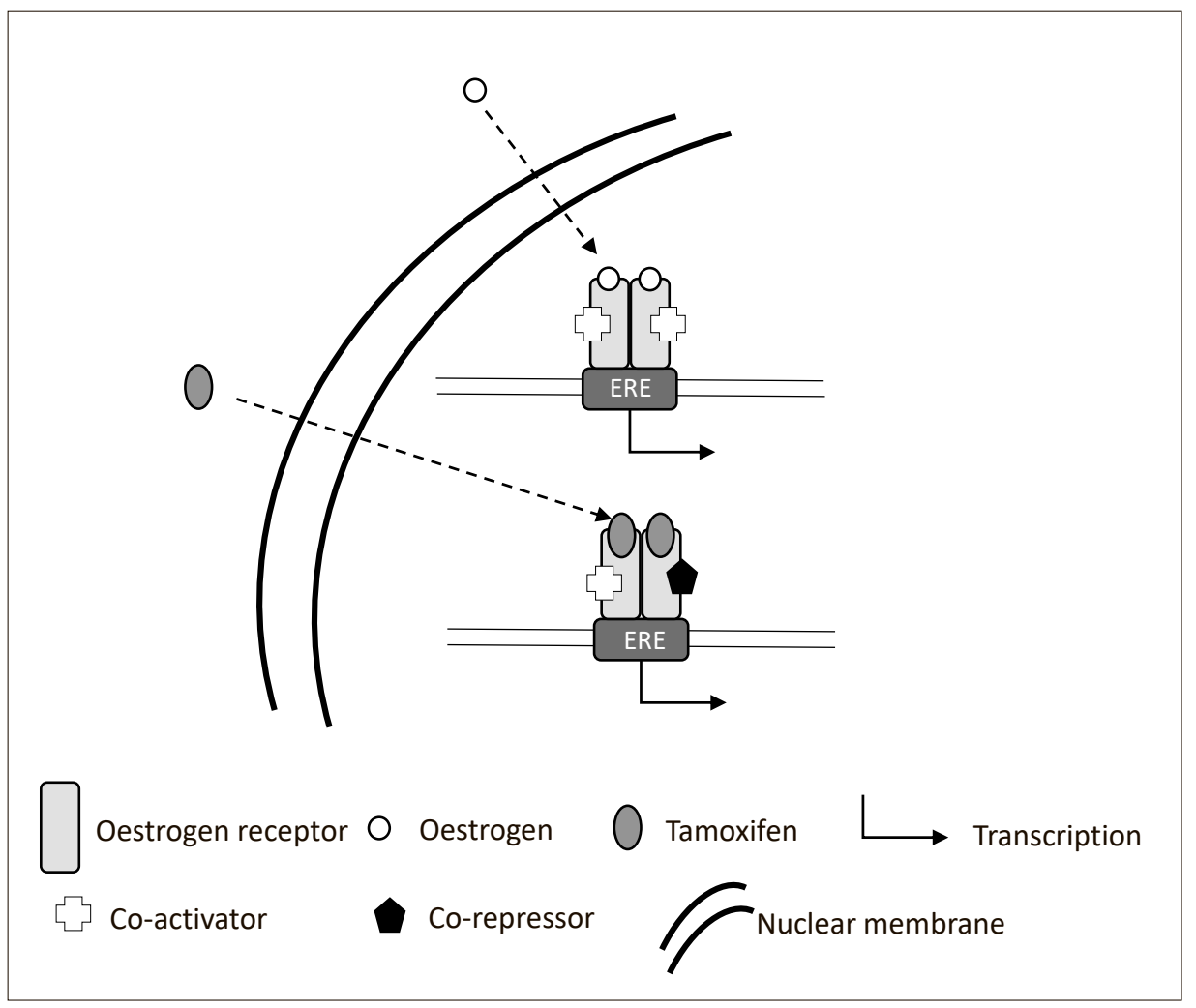

Fig. 2. Oestrogens diffuse through the nuclear membrane and bind to the oestrogen receptors. This leads to a conformational change that allows various co-activators and co-repressors to bind to the dimerised receptor. The receptor complex then binds to specific sequences in the genome, oestrogen response elements (EREs) where it activates transcription of certain genes. Tamoxifen, a selective oestrogen receptor modulator (SERM), and tamoxifen metabolites compete with oestrogens for binding to oestrogen receptors. Depending on which tissue they act, binding of tamoxifen or its active metabolites leads to the recruitment of different sets of co-activators and co-repressors allowing them to activate or inhibit transcription of genes.

plemented with $100 \mathrm{mg} / \mathrm{kg}$ tamoxifen, corresponding to a daily dose of $10 \mathrm{mg} / \mathrm{kg}$. During the treatment period, the mice underwent a variety of non-invasive tests to study the effect of the drug on disease progression and muscle strength. Treated $m d x^{5 C v}$ mice and untreated wild type male and female mice were subjected to a wire grip test and in situ triceps force recordings were performed in terminally anaesthetized mice at 16 months of age. During this study, tamoxifen was shown to drastically improve muscle function and morphology of the $m d x^{5 C v}$ mice; they were less susceptible to fatigue, had larger muscles that produced more force, fibrosis in the heart was reduced and diaphragm morphology greatly improved. Analysis of oestrogen receptor proteins revealed that $\mathrm{ER} \alpha$ and ER $\beta$ were both over-expressed in dystrophic muscle. While treatment with tamoxifen did not affect the levels of ER $\alpha$, it did affect the levels of ER $\beta 2$ isoform, thereby completely normalising the relative ratio between ER $\beta 2$ and ER $\beta 1$. Unpublished data from our lab strongly suggests that tamoxifen and/or its metabolites are prooestrogenic and that the observed beneficial effects are occurring via the ERs and an enhancement of oestrogenic signal- ling. Based on these results, tamoxifen was granted an orphan drug designation (ODD) status for the treatment of DMD in 2017 by the European Medicines Agency (EMA) (EU number: EU/3/17/1944) and a multi-centre, randomised, placebo-controlled phase 3 clinical trial is to start in 2018 to assess the efficacy of tamoxifen in DMD boys (ClinicalTrials.gov Identifier: NCT03354039).

The effect of tamoxifen on dystrophic muscle occurred independently of the underlying cause of the disease, i.e. the lack of dystrophin. In addition to this, tamoxifen appeared to improve dystrophic muscle quality through signalling pathways involving oestrogen receptors. Based on the above we hypothesised that modulating oestrogen signalling in muscle could be a potential therapeutic target for treating a wide range of muscle diseases. To further investigate this, our lab has generated $m d x^{5 C v}$ mice crossed with mice bearing floxed oestrogen receptors. In the resulting multiple mutant mice, ER $\alpha$ and/or ER $\beta$ can be invalidated from skeletal muscles in a time-controlled manner upon doxycycline treatment. ${ }^{[25-27]}$ Since tamoxifen may be working through high affinity oestrogen receptors, studies into the effect of tamox- 
ifen in other, unrelated, muscle disorders are underway, one of which is currently under revision.

Tamoxifen is a safe drug that is already used to treat a variety of conditions in men, women and children. ${ }^{[28-31]}$ Its status as a SERM makes it a suitable drug for treating muscular diseases. Here, repurposing tamoxifen for the treatment of DMD has been briefly described. Tamoxifen had a dramatic effect on the disease independently of the underlying cause, likely through the ER-signalling pathway(s). Although the exact mechanisms of action are not yet known, several molecular analysis approaches (proteomic, genomic and metabolomic) may enable us to find the commonalities between the tamoxifentreated animals and thus, bringing us onestep closer to finding a treatment.

We are moving towards an era where the concept of diseases is widening and there is increasingly an idea of spectrum, with overlapping faulty mechanisms being involved in more than one disease and leading to different phenotypes. With rising costs and increased risks involved in bringing new drugs to the market, the idea of having one drug to treat one disease is quickly falling by the wayside. In addition, patients and their caretakers are becoming more and more knowledgeable and involved in the process, thus increasing pressure to find cures for many rare diseases. The idea of repurposing drugs is not a new one and increasing effort is being put into cataloguing and systematically referencing potential compounds. ${ }^{\text {[2] }] ~ W i t h ~ a n ~ O D D ~ a n d ~}$ a clinical trial in DMD patients starting in 2018, tamoxifen is likely to be next on the growing list of repurposed drugs, and one of the most potent identified so far for severe muscular diseases.

\section{Received: March 2, 2018}

[1] J. P. Hughes, S. S. Rees, S. B. Kalindjian, K. L. Philpott, Br. J. Pharmacol. 2011, 162, 1239.

[2] J. J. Hernandez, M. Pryszlak, L. Smith, C. Yanchus, N. Kurji, V. M. Shahani, S. V. Molinski, Front. Oncol. 2017, 7, 1

[3] N. Deconinck, B. Dan, Pediatr. Neurol. 2007, $36,1$.

[4] N. Wein, L. Alfano, K. M. Flanigan, Pediatr. Clin. North Am. 2015, 62, 723

[5] H. M. Ismail, O. M. Dorchies, L. Scapozza, Exp. Opin. Orphan Drugs 2018, Epub ahead of print, doi: 10.1080/21678707.2018.1452733.

[6] E. Simpson, G. Rubin, C. Clyne, K. Robertson, L. O'Donnell, M. Jones, S. Davis, Trends Endocrinol. Metab. 2000, 11, 184.

[7] J. Blakemore, F. Naftolin, Physiology 2016, 31, 258.

[8] A. A. Larionov, D. A. Vasyliev, J. I. Mason, A. F. Howie, L. M. Berstein, W. R. Miller, J. Steroid Biochem. Mol. Biol. 2003, 84, 485.

[9] A. Wiik, M. Ekman, O. Johansson, E. Jansson, M. Esbjörnsson, Histochem. Cell Biol. 2009, $131,181$.

[10] A. Tobar, M. N. Lutfiyya, Y. Mabasa, H. Meena, C. McGrath, S. Brady, C. Aguero, R. Bales, M. King, Rural Remote Health 2009, 9, 1186.

[11] F. Le Dily, M. Beato, Int. J. Mol. Sci. 2018, 19, 306.

[12] C. J. Gruber, D. M. Gruber, I. M. L. Gruber, F. Wieser, J. C. Huber, Trends Endocrinol. Metab. 2004, 15, 73.

[13] S. Nilsson, S. Mäkelä, E. Treuter, M. Tujague, J. Thomsen, G. Andersson, E. Enmark, K Pettersson, M. Warner, J. A. Gustafsson, Physiol. Rev. 2001, 81, 1535.

[14] D. A. Lowe, K. A. Baltgalvis, S. M. Greising, Exerc. Sport Sci. Rev. 2011, 38, 61.
[15] D. R. Taaffe, S. Sipila, S. Cheng, J. Puolakka, J. Toivanen, H. Suominen, Clin. Physiol. Funct. Imag. 2005, 297.

[16] S. Sipilä, D. R. Taaffe, S. Cheng, J. Puolakka, J. Toivanen, H. Suominen, Clin. Sci. 2001, 101, 147.

[17] R. Sarwar, B. B. Niclos, O. M. Rutherford, J. Physiol. 1996, 493, 267.

[18] R. Julian, A. Hecksteden, H. H. K. Fullagar, T. Meyer, PLoS One 2017, 12, e0173951.

[19] A. L. Moran, G. L. Warren, D. Lowe, J. Appl. Physiol. 2006, 100, 548.

[20] V. C. Jordan, Nat. Rev. Drug Discov. 2003, 2, 205.

[21] E. R. Nelson, S. E. Wardell, D. P. McDonnell, Bone 2013, 53, 42.

[22] R. R. Love, R. B. Mazess, H. S. Barden, S. Epstein, P. A. Newcomb, V. C. Jordan, P. P. Carbone, D. L. DeMets, N. Engl. J. Med. 1992, 326,852 .

[23] M. N. Singh, P. L. Martin-Hirsch, F. L. Martin, Med. Sci. Monit. 2008, 14, RA144.

[24] O. M. Dorchies, J. Reutenauer-Patte, E. Dahmane, H. M. Ismail, O. Petermann, O. Patthey-Vuadens, S. A. Comyn, E. Gayi, T. Piacenza, R. J. Handa, L. A. Décosterd, U. T. Ruegg, Am. J. Pathol. 2013, 182, 485.

[25] M. Chen, A. Wolfe, X. Wang, C. Chang, S. Yeh, S. Radovick, Mol. Cell. Biochem. 2009, 321, 145 .

[26] A. K. Binder, K. F. Rodriguez, K. J. Hamilton, P. S. Stockton, C. E. Reed, K. S. Korach, Endocrinology 2013, 154, 2174.

[27] P. Rao, D. A. Monks, Dev. Neurobiol. 2009, 69, 401.

[28] M. H. S. E. Darkeh, E. Azavedo, Int. J. Clin. Med. 2014, 5, 1068.

[29] N. C. Kreher, E. A. Eugster, R. Shankar, Pediatrics 2005, 116, 1513.

[30] O. Lapid, J. J. Van Wingerden, L. Perlemuter, J. Pediatr. Endocrinol. Metab. 2013, 26, 803.

[31] E. A. Eugster, S. D. Rubin, E. O. Reiter, P. Plourde, H.-C. Jou, O. H. Pescovitz, J. Pediatr. 2003, 143,60 .

[32] S. M. Corsello, J. A. Bittker, Z. Liu, J. Gould, P. McCarren, J. E. Hirschman, S. E. Johnston, A. Vrcic, B. Wong, M. Khan, J. Asiedu, R. Narayan, C. C. Mader, A. Subramanian, T. R. Golub, Nat. Med. 2017, 23, 405. 